\title{
COMPACTION ASSESSMENT OF RECYCLED AGGREGATES FOR USE IN UNBOUND SUBBASE APPLICATION
}

\author{
Vahid AYAN ${ }^{\mathrm{a}}$, Mukesh C. LIMBACHIYA ${ }^{\mathrm{b}}$, Joshua R. OMER ${ }^{\mathrm{b}}$, Seyyed Masoud Nasr AZADANI \\ ${ }^{a}$ Department of Civil Engineering, Islamic Azad University, Islamshahr Branch, Tehran, Iran \\ ${ }^{b}$ Kingston University, Penrhyn Road, Kingston upon Thames, KT1 2EE, UK \\ ${ }^{c}$ Department of Railway Engineering, Iran University of Science \& Technology, Tehran, Iran \\ Received 30 May 2011; accepted 12 Mar 2012
}

\begin{abstract}
Study was recently conducted at Kingston University to assess the suitability of using recycled concrete aggregate (RCA) and reclaimed asphalt pavement (RAP) in unbound subbase mixtures. The results showed that the use of $100 \%$ recycled aggregates increased the optimum moisture content and decreased the maximum dry density of the subbase materials in comparison with natural aggregates. Moreover, the replacement of RCA by reclaimed asphalt pavement by $50 \%$ decreased the optimum moisture content and increased the maximum dry density in proportion to $100 \%$ RCA. The effects of physical properties on $0 \%$ air void and compaction curve were discussed for each type of subbase. The CBR values of the subbase materials prepared with $100 \%$ RCA is lower than subbase mixture with $100 \%$ natural aggregates. The CBR further decreased for replaced subbase with RAP so that $50 \% \mathrm{RCA}+50 \% \mathrm{RAP}$ is not suitable for unbound subbase from the point of CBR view. In each mix the trend of CBR value was investigated in terms of water content. This research found some significant practical points to use in site works.
\end{abstract}

Keywords: RCA, RAP, CBR, compaction, unbound subbase.

Reference to this paper should be made as follows: Ayan, V.; Limbachiya, M. C.; Omer, J. R.; Azadani, S. M. N. 2014. Compaction assessment of recycled aggregates for use in unbound subbase application, Journal of Civil Engineering and Management 20(2): 169-174. http://dx.doi.org/10.3846/13923730.2013.801882

\section{Introduction}

During the last two decades, various researches were carried out to investigate the possibility of using construction and demolition waste. Recycled aggregates (RA) (DMRB, HD 35/04. 2004) and recycled concrete aggregates (RCA) (BS EN 8500-1 2006) are subjects of debate for application in bases and sub bases. These materials can give different test results depending on their sources.

The compaction behavior of recycled aggregates mixed with $5 \%$ to $25 \%$ sand, cement and brick was evaluated by Melbouci (2009), who made the following observations: (1) addition of $10 \%$ by mass of cement to RCA, leads to the maximum dry density and a low optimum moisture content; (2) Addition to RCA of crushed brick particles having sizes lower than $0.125 \mathrm{~mm}$ produces higher dry density values in comparison to the case of RCA blended with sand; (3) Among all addition of 5\% and $10 \%$ the highest dry density is that of mixes with the cement; (4) Adding 5\% brick or $10 \%$ sand or cement increases the immediate CBR values, the soaked CBR values of the mixes containing crushed brick were less than the corresponding immediate CBR values. The reason is sensitivity of brick to water; (5) The soaked CBR values for RCA mixes containing sand and cement were higher that the immediate CBR values; (6) Maximum punching resistance of the mixture was achieved with addition to RCA of either $5 \%$ of crushed brick or $10 \%$ sand and cement. Poon and Chan (2006) found that the subbase using crushed clay brick as the fine fraction make it less susceptible to moisture variations in comparison with the subbase using RCA as the fine aggregates. Chen et al. (2011) investigated the potential of using fine recycled aggregates powder prepared by fine waste aggregates as filler in asphalt mixture. Comparison with the mixtures with conventional limestone powder showed that using fine recycled aggregates powder improved the water sensitivity, high-temperature properties and fatigue life of asphalt mixture.

Leite et al. (2011) indicated that recycled construction and demolition waste (RCDW) can be utilized as coarse base and subbase layer for low-volume roads. The result of laboratory program showed that the composition and compactive effort effect on the physical characteristics of the RCDW aggregate. The compaction process including intermediate and modified proctor energies, promoted a partial crushing and breakage of RCDW. After compaction the grain-size distribution changed and the percentage of cubic grains increased.

Mills-Beale and You (2009) studied on mechanical properties of asphalt mixtures with RCA for low volume roads. The calculation of compaction energy index (CEI) 
proved that using RCA in the mixes will save some amount of compaction energy. The results revealed that as RCA decreased in the mix, the CEI increases, meaning more equipment compaction energy was expended during the initial compaction before opening the pavement to traffic.

In the comprehensive research by authors different properties of recycled aggregates were tested. For instance, one of these tests were Aggregate Impact Value (AIV) which is a measure of the resistance of aggregate to impact or sudden shock. In this paper, the compaction behavior of RCA blended with reclaimed asphalt pavements as subbase materials were studied. The results were compared with the subbase materials prepared with natural aggregates.

\section{Materials}

The research concentrated on investigating the suitability of three kinds of aggregates which all are Type 1 unbound mixture for subbase (MCHW Series 800 2007) (Fig. 1):

1. $100 \%$ Recycled Concrete Aggregate (RCA) which is indicated with the notation T-1;

2. $100 \%$ Limestone as the natural aggregate (NA) which is indicated with the notation T-2;

3. $50 \%$ Recycled Concrete Aggregate (RCA) $+50 \%$ Reclaimed Asphalt Pavement (RAP) which is indicated with the notation T-3.

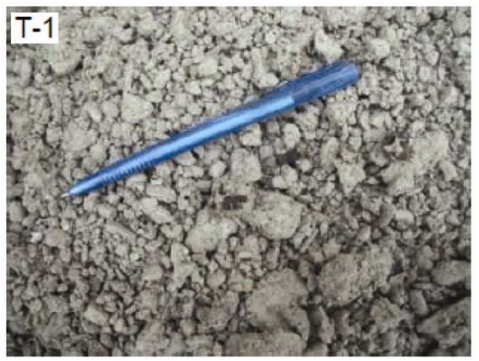

a) Sample of T-1

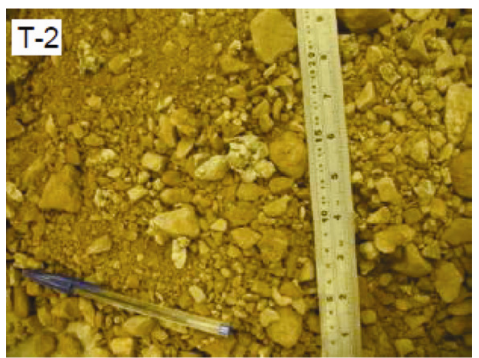

b) Sample of T-2

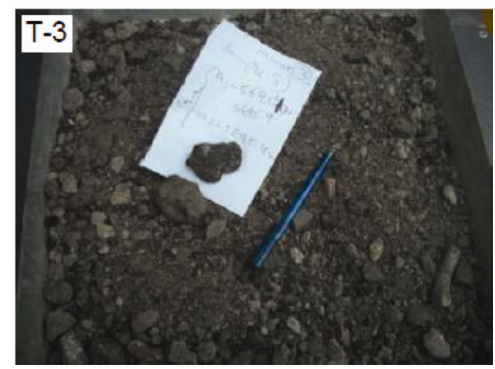

c) Sample of T-3

Fig. 1. Samples of T-1, T-2 and T-3
The grading curves of these three aggregates, the upper and lower range of Type 1 unbound mixtures according to MCHW Series 800 are shown in Figure 2.

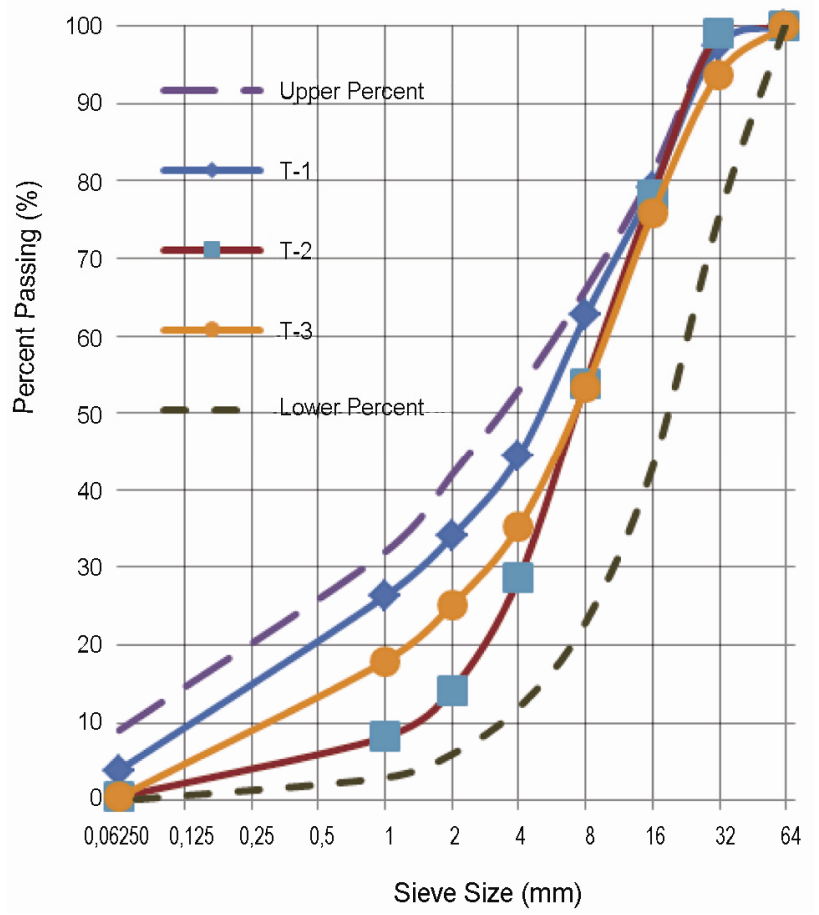

Fig. 2. Grading curves for the tested aggregates

For all three kinds of aggregates the mixture designation was $0 / 31.5 \mathrm{~mm}$, the maximum fines content was $\mathrm{UF}_{9}$ and Oversize was $\mathrm{OC}_{75}$ which meet the requirements of MCHW Series 800 (2007) requirements.

\section{Current specifications}

In this research, the procedures for testing and analysis were governed by relevant documents from British Standards (BS), Specification for Highway Works (SHW), Manual of Contract Documents for Highway Works (MCHW) and Design Manual for Roads and Bridges (DMRB). In MCHW Series 800 (MCHW, Volume 1, SHW, Series 800, 2007), four types of unbound mixtures for subbase are defined (Type-1, Type-2, Type-3 and Type-4). The present research focuses on Type-1 materials. Proctor compaction test was carried out according to compaction BS EN 13286 Part-2. From this Standard, the Proctor mould (B) was used for this work. The reason for the application of mould (B) was related to these facts that all particles were smaller than $100 \mathrm{~mm}$, also $97.4 \%$ of T-1, $98.96 \%$ of T-2 and $93.72 \%$ of T-3 passed the $31.5 \mathrm{~mm}$ test sieve. The diameter of large Proctor cylindrical mould (B) and its height were $150 \mathrm{~mm}$ and $120 \mathrm{~mm}$, respectively. The mass of required sample was $40 \mathrm{~kg}$ and the required specifications for modified Proctor test are summarized below (BS EN 13285 2003):

Mass of rammer $(B)=4.5 \mathrm{~kg}$;

Diameter of rammer $=50 \mathrm{~mm}$;

Height of fall $=457 \mathrm{~mm}$;

Number of layers $=5$;

Number of blows per layers $=56$. 
These conditions increase the compaction effort with a specific energy of about $2.7 \mathrm{MJ} / \mathrm{m}^{3}$.

BS EN13286 part-47 specifies the test methods for the laboratory determination of CBR. The CBR mould and rammer confirming to BS EN 13286-2 were applied.

\section{Method statements}

\subsection{Determination of the moisture-density relation}

To determine the moisture- density relationship, compaction tests were carried out on 5 samples for T-1, 7 samples for T-2 and 8 samples for T-3. All these samples were passing the $31.5 \mathrm{~mm}$ test sieve, while AASHTO designations need materials passing the $4.75 \mathrm{~mm}$ (No. 4) sieve (AASHTO T 180-01). For T-1, the plot of dry density versus water content produced a relatively smooth curve where optimum moisture content was easily identified. In contrast, T-2 and T-3 needed more compaction test samples to produce a reasonable curve. Figure 3 shows the process of drying the T-1 samples with warm air current before compaction to reach the constant mass.

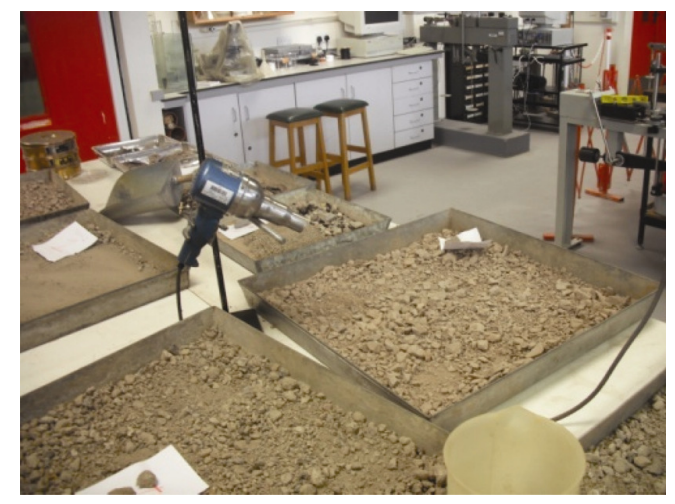

Fig. 3. Drying with warm air dryer

\subsection{Determination of CBR}

For this test, samples were taken from materials having a maximum size of $22.4 \mathrm{~mm}$. As required by BS EN 13286-2, a seating load of $40 \mathrm{~N}$ was applied to the specimen prior to testing since the CBR was expected to be greater than $5 \%$. The CBR tests were carried out for a range of water contents of $1.5 \%-15 \%$, depending on the material tested. The CBR test specimens were prepared in a standard mould in five layers, each one being compacted with 56 blows. In the test, a constant rate of plunger penetration of $1.27 \mathrm{~mm} / \mathrm{min}$ was maintained. The load readings were recorded at penetration increments of $0.25 \mathrm{~mm}$ up to a total penetration $10 \mathrm{~mm}$. From the testcurve, the forces corresponding to the $2.5 \mathrm{~mm}$ and $5 \mathrm{~mm}$ penetration were read. The higher percentage of the reference forces at these penetrations was taken as the CBR value. After the test was completed, the whole CBR specimen, rather than a small sample from the core, was used to determine the water content. This is because of the possibility of moisture migrating from the core towards the periphery of the loaded T-2 specimen. The oven dry mass was achieved by placing the test portion in an oven set at a temperature of $110 \pm 5{ }^{\circ} \mathrm{C}$ for as long as necessary for the specimen to reach a constant mass.

\section{Results and discussion}

This section includes results and correspondence discussion regarding compaction tests and CBR tests on the specimens.

\subsection{Compaction tests}

The optimum moisture content (OMC) and maximum dry density (MDD) were derived from the dry densities and corresponding water contents curves shown in Figure 4. By fitting a polynomial curve through the data points, the values of MDD and OMC were identified as follows:

$-100 \%$ RCA had an OMC of $13.71 \%$ and an MDD of $1.84 \mathrm{~g} / \mathrm{cm}^{3}$;

$-100 \% \mathrm{NA}$ had an OMC of $6.71 \%$ and an MDD of $2.03 \mathrm{~g} / \mathrm{cm}^{3}$;

$-50 \% \mathrm{RCA}+50 \% \mathrm{RAP}$ had an OMC of $10.53 \%$ and an MDD of $1.89 \mathrm{~g} / \mathrm{cm}^{3}$.
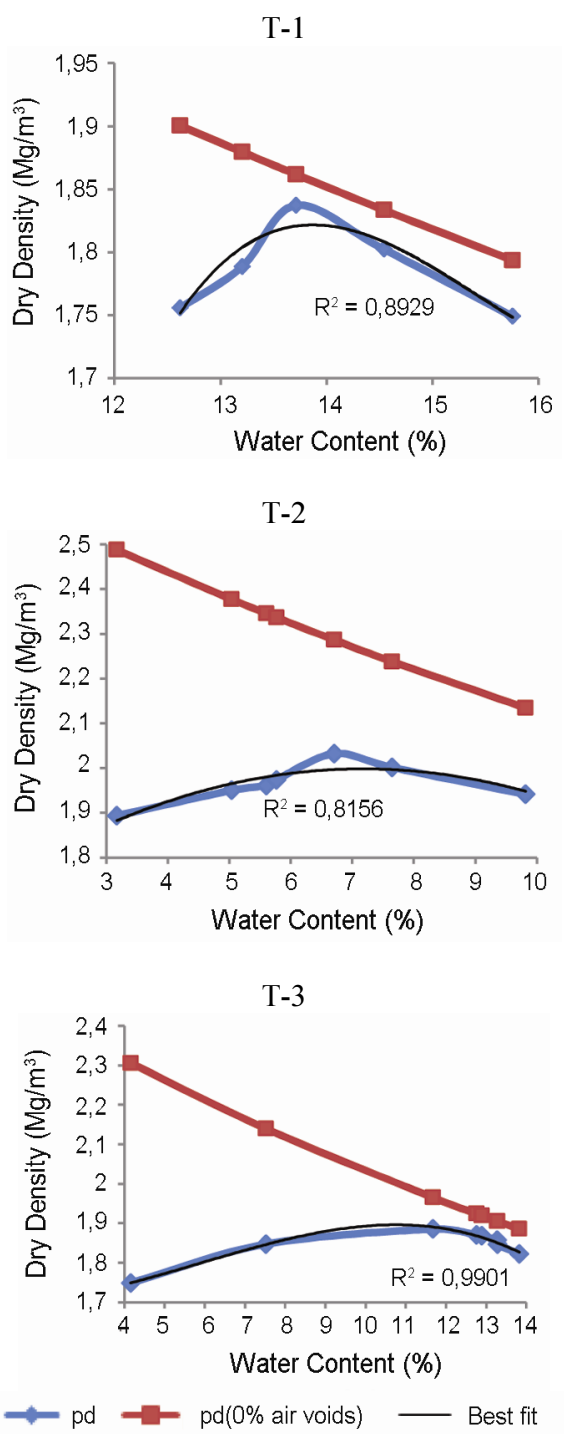

Fig. 4. Dry densities and corresponding water contents of T-1, T-2 and T-3 
During compaction, it was observed that RCA particles broke down into smaller particles compared to NA and RAP. This behavior can be attributed to two reasons: (1) increasing the percentage of fines in a mix resulted in a decrease in dry density and increase in water content; (2) the existing cement mortar adhering to the stone particles in the RCA made a weak, porous and cracked layer (Tam et al. 2007) which decreased the density of them relative to NA. It was observed that in order to achieve effective compaction in OMC the RCA mixes would appear to have some free water but this eventually gets absorbed or consumed by the residual free cement in RCA hydrating during compaction. For the purpose of site works, this point should be noted.

An important factor which distinguishes the properties of RCA and RAP is that the bitumen coated aggregates in RAP form a more flexible material that is less prone to breaking during compaction in comparison to RCA.

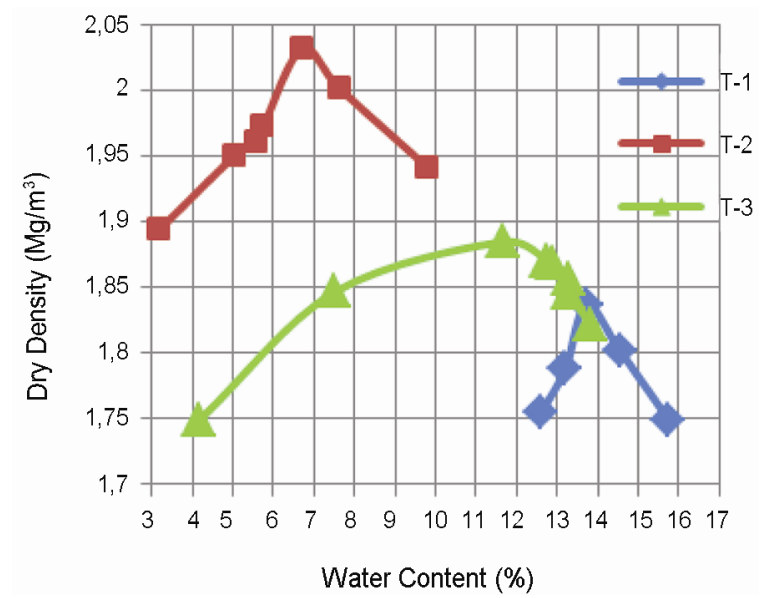

Fig. 5. Moisture- density relationship for three subbase materials

Furthermore, as revealed by the curves in Figure 5, the rate of change of dry density with moisture content is greatest for the mixture containing 100\% RCA (T-1). Therefore it is essential to compact this material at a moisture level very close to the OMC.

As shown in Figure 4, the incorporation of RAP in T-3 moved the compaction curve closer to the $0 \%$ air voids line, particularly on the "wet side" of the compaction curve. This behavior may be due to reasons such as: (a) the regularly shaped aggregates in RAP; (b) the interlocking between the coated aggregates in RAP and the RCA particles. Decreasing the air voids caused aggregates to be saturated and reach a desired level of compaction. The $0 \%$ air voids line for material T-1 was closer to the compaction curve in comparison to the case of material T-2 (Fig. 4). This implies that the RCA became more saturated than NA at optimum moisture content. This difference was mainly attributed to physical properties and the shape of RCA particles after breaking under rammer blows. The RCA particles were broken more easily than the more rounded NA, thereby allowing crushed cement paste to fill the voids and the coarse particles to interlock firmly with each other.
As the density of cement mortar (around 1.0$\left.1.6 \mathrm{Mg} / \mathrm{m}^{3}\right)(\mathrm{Tam}, \mathrm{Le} 2007)$ is less than that of stone particles of about $2.60 \mathrm{Mg} / \mathrm{m}^{3}$, the smaller the particle density, the higher the cement mortar content adhering to the RCA. The reason for the particle densities being lower in RCA as compared to NA is due to the relatively high porosity and low density of the cement paste adhering to the RCA particles.

Previous research (Ayan 2011; Ayan et al. 2011) for water absorption based on (BS EN 1097-6 2000) showed that the water absorption of RCA is more than four times higher than NA. Conversely, bulk density of RCA is almost $8 \%$ lower than NA. The presence of RCA in T-1 and T-3 increased the OMC and decreased the MDD as a result of the high water absorption and the low particle density of the recycled concrete aggregates.

\subsection{CBR tests}

Graphs of moisture versus CBR with the second degree best fit curves are plotted in Figure 6 to compare the properties of the three kinds of aggregates:

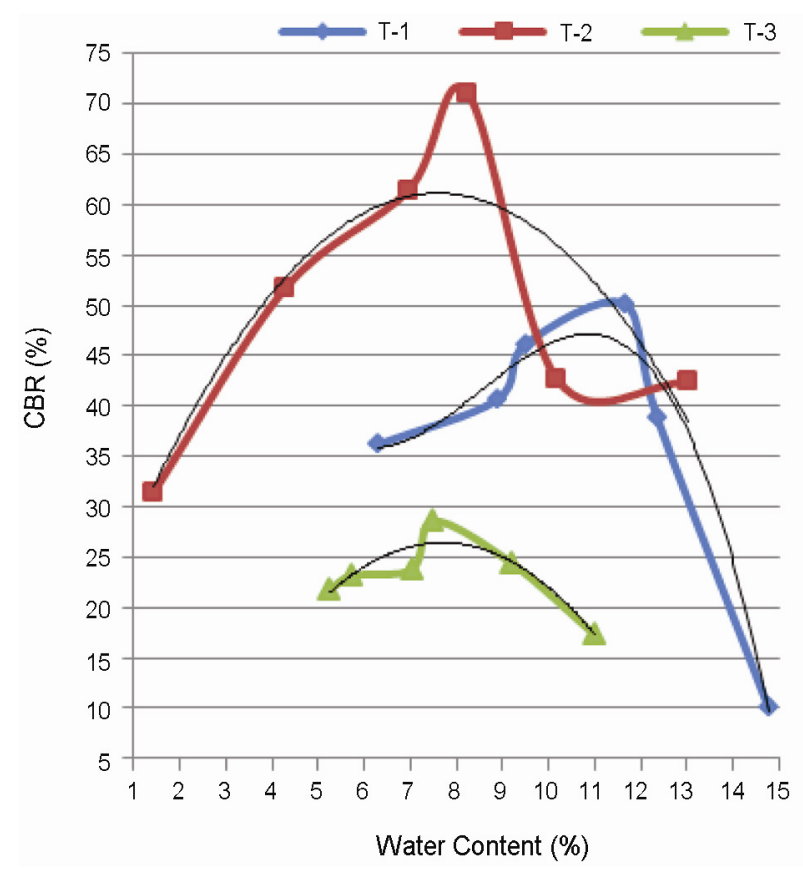

Fig. 6. Moisture-CBR curves

Figure 6 indicates that the CBR of T- 1 was more susceptible to the moisture variation on the wet side. It is seen (Fig. 6) that, the sensitivity of CBR to moisture content is more pronounced on the wet side of the compaction curve than on the dry side. The maximum CBR was gained at about $11 \%$ water content.

Plots of moisture content versus dry density are shown in Figure 7 achieved from compacted specimens (finer than $22.4 \mathrm{~mm}$ ) of CBR test. This figure shows that the specimen of material T-1 having the lowest degree of compaction attained a dry density of $96 \%$ of the MDD and for this the CBR was $36 \%$. This CBR was more than a laboratory CBR of $30 \%$ recommended by DMRB (1994) for granular subbase. For $100 \%$ compaction the 
CBR value became $47 \%$. According to Figure 7 for the aggregates of $\mathrm{T}-2$ the maximum CBR was gained at $8.24 \%$ (Fig. 6) water content. The behaviour of this kind of aggregates in both wet and dry sides of curve was approximately the same.

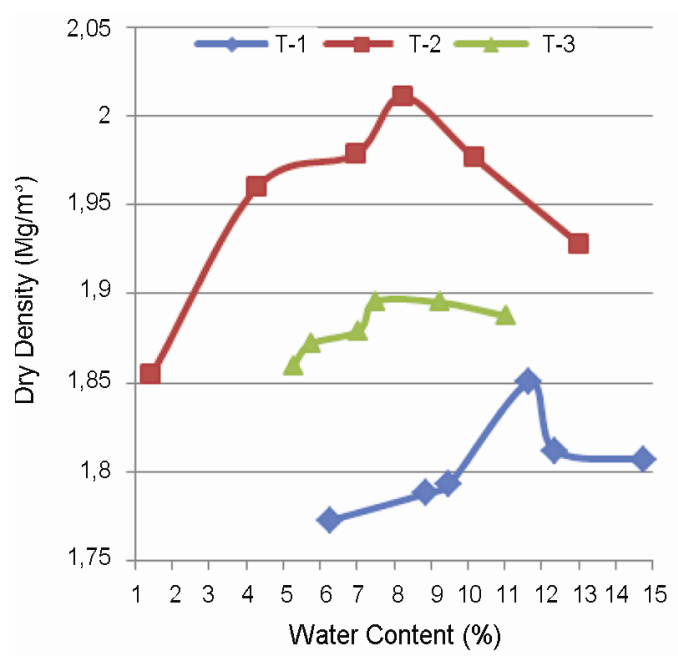

Fig. 7. Dry density versus water content

Figure 7 also shows that for material T-2, the specimen compacted to the lowest degree achieved $91 \%$ of the MDD and a corresponding CBR value of $32 \%$. This also meets the requirement of $30 \%$ minimum CBR for a subbase layer.

Demolished concrete came from different sources and due to crushing their fine particles and cement were separated. This process probably produced irregularly shaped and rough surfaced particles which possibly increased the amount of voids within the material even after compaction and led to a decrease in the MDD.

From Figure 6 it was found that the CBR of T-3 as $\mathrm{T}$-1 was more responsive to moisture variation on the wet side than on the dry side. The maximum CBR was gained at about $7.52 \%$ water content. The MDD determined for T-3 was $1.89 \mathrm{~g} / \mathrm{cm}^{3}$, which means the compacted densities range of the last three specimens are higher than $100 \%$ of the maximum dry density. All CBR values for T-3 were less than $30 \%$, implying that this mix is not suitable for subbase application. Compacting T-3 at its OMC would give a CBR value of $29 \%$ (Fig. 7). To enhance this value for use in a subbase, some modification in particle size distribution of the mixture will be required.

\section{Conclusions}

This paper presents the result of an investigation of compaction and CBR tests for recycled concrete aggregates and reclaimed asphalt pavement as possible materials for use in unbound subbases. Comparison with limestone natural aggregates properties reveals their suitability or unsuitability. The following conclusions can be made from the present research:

- Hydrated cement as fine in addition to unhydrated cement with low density remained in the mortar as an important constituent of RCA decrease the density and increases the water content;

- The graphs of water content and dry density from compaction and CBR tests revealed that the mixtures made with the recycled materials were likely to be influenced by moisture variation on the wet side of OMC than on the dry side of the OMC. With regard to this fact that in the dry side the aggregates have got more permeability and shear resistance but the wet side has got the converse effect (Scroochi, Sedighi Manesh 2009), on the other hand the unbound subbases need to drain surface water; the subbase prepared with recycled material must be compacted on the dry side, i.e. with moisture less than $\mathrm{OMC}$;

-For given moisture content the samples having $50 \%$ RAP $+50 \%$ RCA exhibited the lowest CBR values. CBR values of $100 \%$ RCA are less than those of natural aggregates, at any given water content;

- Samples made with $50 \%$ RAP $+50 \%$ RCA produced a CBR value of $29 \%$, which falls below the minimum requirement for unbound subbase application.

\section{References}

Ayan, V. 2011. Assessment of recycled aggregates for use in unbound sub-base application: $\mathrm{PhD}$ Thesis. Kingston University, London.

Ayan, V.; Limbachiya, M. C.; Azadani, S. M. N. 2011. A study into the absorption property of recycled concrete and reclaimed asphalt mixes, in Proc. of the $5^{\text {th }}$ International Conference Bituminous Mixtures \& Pavements, 2-3 June, 2011, Thessaloniki, Greece.

American Association of State Highway and Transportation Officials (AASHTO). 2004. Standard method of test for moisture-density relations of soils using a 4.54(10-lb) rammer and 457-mm (18-in.) drop. AASHTO Designation: T 180-01.

BS EN 1097-6. 2000. Tests for mechanical and physical properties of aggregates. Part 6: determination of particle density and water absorption. London, British Standard Institution.

BS EN 13285.2003. Unbound mixtures specification. London, British Standard Institution.

BS EN 13286-2.2004. Unbound and hydraulically bound mixtures. Part 2: test method for the determination of the laboratory reference density and water content-proctor compaction. London, British Standard Institution.

BS EN 13286-47.2004. Unbound and hydraulically bound mixtures. Part 47: test method for the determination of California bearing ratio, Immediate bearing index and linear swelling. London, British standard Institution.

BS EN 8500-1. 2006. Concrete - complementary British standard to BS EN 206-1. Part 1: method of specifying and guidance for the specifier. London, British standard Institution.

Chen, M.; Lin, J.; Wu, S. 2011. Potential of recycled fine aggregates powder as filler in asphalt mixture, Construction and Building Materials 25(10): 3909-3914. http://dx.doi.org/10.1016/j.conbuildmat.2011.04.022

Leite, F. D. C.; Motta, R. D. S.; Vasconcelos, K. L.; Bernucci, L. 2011. Laboratory evaluation of recycled construc- 
tion and demolition waste for pavements, Construction and Building Materials 25(6): 2972-2979.

http://dx.doi.org/10.1016/j.conbuildmat.2010.11.105

Melbouci, B. 2009. Compaction and shearing behaviour study of recycled aggregates, Construction and Building Materials 23(8): 2723-2730.

http://dx.doi.org/10.1016/j.conbuildmat.2009.03.004

Mills-Beale, J.; You, Z. 2010. The mechanical properties of asphalt mixtures with recycled concrete aggregates, Construction and Building Materials 24(3): 230-235. http://dx.doi.org/10.1016/j.conbuildmat.2009.08.046

Poon, C. S.; Chan, D. 2006. Feasible use of recycled concrete aggregates and crushed clay brick as unbound road subbase, Construction and Building Materials 20(8): 578585. http://dx.doi.org/10.1016/j.conbuildmat.2005.01.045

Scroochi, A. M.; Sedighi Manesh, M. 2009. Soil mechanics laboratory. Tehran (in Persian).

Tam, V. W. Y.; Le, K. N. 2007. Aggregate testing using 2nd-, 7 th- and 10th-order interpolation polynomials, Resources, Conservation and Recycling 52(1): 39-57. http://dx.doi.org/10.1016/j.resconrec.2007.02.001
Tam, V. W. Y.; Tam, C. M.; Le, K. N. 2007. Removal of cement mortar remains from recycled aggregate using presoaking approaches, Resources, Conservation and Recycling 50(1): 82-101.

http://dx.doi.org/10.1016/j.resconrec.2006.05.012

The Highway Agency. 1994. Design manual for roads and bridges (DMRB). Vol. 7, Section 2, Part 2, HD 25/94: Foundations.

The Highway Agency. 2004. Design manual for roads and bridges (DMRB). Vol. 7, Section 1, Part 2, HD 35/04: Conservation and the use of secondary and recycled materials.

The Highway Agency. Standards for Highways. 2007. Manual of contract document for highway works (MCHW). Vol. 1, Specification for Highway Works. Series 800, Road Pavements - Unbound, Cement and Other Hydraulically Bound Mixtures.

Vahid AYAN is an Assistant Professor in Civil/Highway and Transportation Engineering, at IAU University, Iran which he joined in 1998. He is a graduate of the Universities of Tabriz and Tehran and is a Chartered Civil Engineer in Iran. His career in Civil Engineering commenced as a Site Engineer with major Civil Engineering contractors and few years with Highway and Railway Engineering consultants on a wide variety of highway construction, maintenance, rehabilitation and asphalt recycling works as a Project Manager. He was awarded a scholarship for his doctoral study after achieving over ten years practical and academic experiences. He worked on application of recycled aggregates as pavement materials for his $\mathrm{PhD}$ research at Kingston University London, and was graduated on 2012. He is a present or past member of several international committees and societies such as: ACI-Iran Branch, The Institution of Structural Engineering (ICE), Royal Institution of Chartered Surveyors (RICS), The Institution of Highway \& Transportation (IHT), The Charted Institute of Building (CIOB), American Society of Civil Engineers (ASCE), ASTM International. He has served as a reviewer for leading journals and conferences such as International Journal of Pavement Engineering.

Mukesh C. LIMBACHIYA is a Professor of Civil Engineering and Head of School of Civil Engineering and Construction at Kingston University. He is a Chartered Engineer and has a particular expertise in Sustainability and an experienced Researcher and Lecturer in Civil Engineering, Construction Materials and Management, and keen interest in Infrastructure Development for Modern Built Environment.

Joshua R. OMER holds a First Class Honours degree in Civil Engineering, an MSc in Structural Engineering and a PhD in Geotechnical Engineering. He was awarded a Scholarship for his doctoral studies by the Association of Commonwealth Universities. He has been a Fellow of The Royal Society and was the winner of the 1994 David Douglas Prize and Lecture, a prestigious biannual prize awarded for engineering excellence by the South Wales Institute of Engineers. He is a past recipient of a Research and Development award of the Institution of Civil Engineers. He is also currently a member of the editorial board of the International Journal of Geotechnical Engineering. He has over 20 years of experience in lecturing and consultancy in civil engineering. He has worked for a number of universities and companies both in UK and overseas. He has undertaken design and supervision of various structural and civil engineering projects. He has developed interactive computer software for analysis of deep foundations. In research, he has supervised several MSc and PhD students in addition to contributing a large number of research papers in reputable journals and conferences. He has served as a Reviewer for leading journals such as the ASCE Journal of Geotechnical and Geo-environmental Engineering. He was a Committee Member of the World Congress on Engineering held in London in July 2007 under the auspices of the International Association of Engineers

Seyyed Masoud Nasr AZADANI is an Assistant Professor in Asphalt and Pavement and recently continued his research in railway track maintenance. 